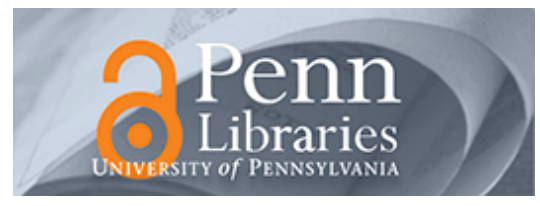

University of Pennsylvania ScholarlyCommons

January 2006

\title{
The Social Diffusion of Influence Among Adolescents: Group Interaction in a Chat Room Environment About Antidrug Advertisements
}

Clarissa David

University of Pennsylvania

Joseph N. Cappella

University of Pennsylvania, jcappella@asc.upenn.edu

Martin Fishbein

University of Pennsylvania, mfishbein@asc.upenn.edu

Follow this and additional works at: https://repository.upenn.edu/asc_papers

\section{Recommended Citation}

David, C., Cappella, J. N., \& Fishbein, M. (2006). The Social Diffusion of Influence Among Adolescents: Group Interaction in a Chat Room Environment About Antidrug Advertisements. Communication Theory, 16 (1), 118-141. https://doi.org/10.1111/j.1468-2885.2006.00008.x

This paper is posted at ScholarlyCommons. https://repository.upenn.edu/asc_papers/101

For more information, please contact repository@pobox.upenn.edu. 


\title{
The Social Diffusion of Influence Among Adolescents: Group Interaction in a Chat Room Environment About Antidrug Advertisements
}

\begin{abstract}
One route to influence in mass communication campaigns to reduce risky behavior is through interpersonal discussion of the content of the campaign and other behaviors pertinent to those targeted by the campaign. The goal of this study was to test the effects of online group interaction among adolescents about anti-marijuana advertisements on relevant attitudes and behaviors. A between subjects post only experimental design was used to test two crossed factors, online chat and strength of arguments in antidrug ads. A sample of 535 students was randomly assigned to one of four conditions: chat and strong argument ads, chat and weak argument ads, no chat and strong argument ads, and no chat and weak argument ads. The group interactions about antidrug ads lead to negative effects such that those who chatted reported more pro-marijuana attitudes and subjective normative beliefs than those who just viewed the ads. No support was found for the hypothesis that strong argument ads would result in more antidrug beliefs relative to weak argument ads in either the chat or the no chat conditions. Overall, these findings suggest that viewing antidrug ads and discussing them with peers may result in deleterious effects in adolescents.
\end{abstract}




\title{
The Social Diffusion of Influence Among Adolescents: Group Interaction in a Chat Room Environment About Antidrug Advertisements
}

\author{
Clarissa David, Joseph N. Cappella, \& Martin Fishbein \\ Annenberg School for Communication, University of Pennsylvania, Philadelphia, PA 191046220
}

\begin{abstract}
One route to influence in mass communication campaigns to reduce risky behavior is through interpersonal discussion of the content of the campaign and other behaviors pertinent to those targeted by the campaign. The goal of this study was to test the effects of online group interaction among adolescents about antimarijuana advertise ments on relevant attitudes and behaviors. A between subjects post only experimental design was used to test two crossed factors, online chat and strength of arguments in antidrug ads. A sample of 535 students was randomly assigned to one of four condi tions: chat and strong argument ads, chat and weak argument ads, no chat and strong argument ads, and no chat and weak argument ads. The group interactions about antidrug ads lead to negative effects such that those who chatted reported more promarijuana attitudes and subjective normative beliefs than those who just viewed the ads. No support was found for the hypothesis that strong argument ads would result in more antidrug beliefs relative to weak argument ads in either the chat or the no chat conditions. Overall, these findings suggest that viewing antidrug ads and discussing them with peers may result in deleterious effects in adolescents.
\end{abstract}

Public communication campaigns operate in a complex social environment. The effects of campaigns are not simply from the mass media to individuals (i.e., direct effects), but they also have indirect effects through institutional and interpersonal routes (Hornik \& Yanovitzky, 2003). Campaign effects that happen through social diffusion are part of a long-standing tradition of mass communication effect studies investigating the role of personal influence on opinion (Katz \& Lazarsfeld, 1955). Interpersonal communication plays an important role in facilitating or inhibiting processes through which mass communication affects audiences' opinions (Price, 1992) and their willingness to accept ideas and innovations (Rogers, 1995). 
Much of the available literature assumes that generating "buzz" about a topic or innovation will lead to effects that are in line with a campaign's message. The study of conditions that engender negative effects of social diffusion processes remains largely unexplored. In The Anatomy of Buzz, Rosen (2000) argues that activating communication networks about a focal issue-whether the issue is a commercial product, an idea, or a social or technological innovation-can help to diffuse the concept, product, or behavior within the communication network. Rogers (1962) made similar assumptions about the role of interpersonal communication in the diffusion of innovations. But some influence processes might actually be undermined by negative comments circulating as a part of the buzz.

By "negative" effects, we mean not just the absence of successful diffusion of an innovation, nor simply the failure of a health campaign to reduce risky behavior, but also the occurrence of a boomerang - the opposite effect to that intended by a campaign. Although most theorists - and certainly practitioners —assume that conversations about a campaign's messages propel effects in a direction consistent with the campaign's goals, certain conditions can produce the opposite effects. In this article, we propose a framework for examining such conditions for the social influence route to effects and test parts of the framework in the context of an antidrug campaign directed at adolescent marijuana use. We do not attempt to offer a theoretical framework for campaign boomerang effects in general but more narrowly for boomerang through social influence.

\section{Campaigns do fail}

Meta-analyses of health campaigns suggest that they have overall small positive effects (Snyder \& Hamilton, 2002). There are few examples of campaigns that have produced consequences contrary to its stated purpose-possibly because of biases that interfere with reporting such cases. These include biases against publication, organizers ending a campaign before more damage can be done, and the fact that many campaigns are not evaluated or are not evaluated by a neutral party.

One example of a campaign that may have produced negative consequences is the National Youth Anti-Drug Media Campaign (NYADMC). Published campaign evaluations report unfavorable social norm trends in the youth population sampled, as well as an unfavorable effect for intentions to use marijuana for the 14- to 18year-old subgroup (Hornik et al., 2001). Other examples of iatrogenic effects include alcohol and drug prevention (Foxcroft, Lister-Sharp, \& Lowe, 1997; Wechsler et al., 2003; Werch \& Owen, 2002).

In these few publicly available cases, we have no direct evidence that the reason for the boomerang is the circulation of commentary among members of the target audience that undermines the campaign's purposes or its messages. Because the routes of influence are complex and intertwined, and because there are so few cases, there is little data on hand to extend theories of social influence to include socially diffused negative campaign effects.

However, in more controlled and smaller scaled contexts, where social interaction can be followed through observation, some evidence of deleterious effects of 
social communication is available. Dishion and his colleagues (Dishion, McCord, \& Poulin, 1999; Dishion, Poulin, \& Burraston, 2001) have reported findings that suggest that social interactions among adolescents with a history of risky behavior-even in the presence of trained moderators-can have the unfavorable effect of creating a kind of "deviancy training" producing, in some circumstances, shortand long-term increases in risky behavior. The Adolescent Transitions Program Study was undertaken to test a theoretical model of problem behavior in adolescents. The study compared the effects of parent-focused and teen-focused group-based interventions. Although there were positive short-term effects, such as improved family relations in some conditions, the long-term effects were generally undesirable. At the 3-year follow-up, the teen-focused program in particular was found to be associated with increased delinquent behaviors (Dishion \& Andrews, 1995). Older youths who had higher initial levels of problem behavior were more likely to experience negative effects. Focus group sessions suggested that older children attract more group attention than the younger and less deviant members (Dishion et al., 1999).

The aggregation of high-risk youth, particularly older and more deviant adolescents, is clearly a risky strategy for health interventions. When campaigns activate communication about their messages, discussion among peers can be encouraged that in turn leads to negative effects. Dishion's studies suggest a model for research in a more limited, controlled setting that allows for observing consequences of social interaction contrary to that intended by an intervention.

\section{Components of a theory of social influence}

When a message from the news media, campaign source, or public health official is disseminated, the role of social communication in intensifying, mitigating, or reversing the message's effects depends on several considerations: (a) Will the message, once received, produce conversation (aka buzz) among members of the target audience? (b) Given social communication about the campaign's message or goals, who will be the most likely communicators? (c) Will those most likely to communicate be those disposed toward producing communication favorable toward the message or those opposed to it? and (d) Under what conditions will social communication (positive and negative) influence other's beliefs, attitudes, social norms, or intentions? Answering these four questions provides a framework within which to explain and predict conditions for boomerang through social communication.

In the limited venue of this article, we will not try to answer these questions in general. Instead, we will narrow our focus in two ways: first, by focusing on what has been ignored-negative social comments in response to a campaign or other intervention; and second, by focusing on a particular application where social influence can be followed and where the occurrence of contrary comments is possible and even likely, that is, discussion among adolescents about risky behavior specifically marijuana use. 


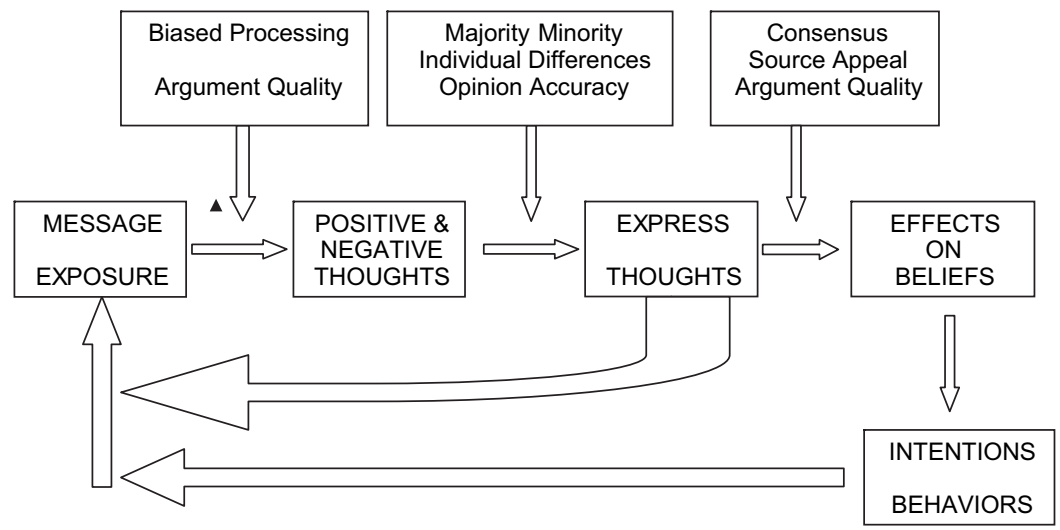

Figure 1 Model for social influence.

Figure 1 offers a general framework within which questions about social influence processes can be embedded both for our particular application and for other applications.

Step 1, the "message exposure" segment, specifies a necessary condition for social influence through a campaign. Without exposure to the message, there can be no possibility of any social influence generated by the campaign (Hornik \& Yanovitzky, 2003).

Step 2 in the model describes the fact that given exposure to the campaign and its message(s), thoughts about the campaign's themes are created. These thoughts can be favorable or unfavorable ones and, of course, low-intensity campaigns or disinterest among the target audience may lead to no thoughts. But key here is the moderating effects on whether positive and negative thoughts occur. Following the principles of "cognitive response analysis" (Greenwald, 1968; Petty, Ostrom, \& Brock, 1981) and the Elaboration Likelihood Model (ELM) (Petty \& Cacioppo, 1986), we assume that two factors are crucial to discriminating positive and negative thoughts, namely, biased processing and the strength of the arguments making up the campaign's message.

Step 3 assumes that a member of the target audience has either favorable or unfavorable thoughts toward the campaign's message and is facing the possibility of sharing those thoughts with others in his or her immediate social network. Many factors can enter the decision to communicate or not: opportunity, the size of the network of eligible others, the topic's degree of taboo within the social group, and so on. Two factors loom large: individual differences in expressiveness and perception of minority-majority status regarding the opinions to be expressed. Although those with a disposition toward being expressive and who perceive that they hold an opinion shared by the majority will be most likely to express their views, minority opinion can lead to expression in some circumstances and perceptions of what opinion is held by the majority can be incorrect. 
Step 4 assumes that once an opinion is expressed to another, it can have a variety of possible effects that we represent through the components of the integrated model of behavior change (IMBC) (Fishbein et al., 2002). Depending on what thoughts are expressed, these social messages prompted by the campaign could affect beliefs about the behavior targeted by the campaign, beliefs about which social groups support or oppose the behavior, or beliefs about how easy or difficult it is to control the behavior (i.e., efficacy). The IMBC directs our attention to the impact of social communication about the campaign on behavioral beliefs, social normative beliefs, and efficacy beliefs as mediators of impact on intention and behavior. ${ }^{1}$ Whether beliefs are affected by other's comments will depend on their persuasive appeal, including, we expect, typical aspects of persuasive effect-consensus, the appeal of the source, and the quality of the arguments.

In addition, two feedback loops are added. One, from "expressed arguments," recognizes that messages delivered through social routes become a part of the messages about the campaign topic that are circulating in the social environment. The second, from the "intentions and behavior" component, recognizes that behaviors enacted in the social environment can produce effects through modeling (Cialdini, 2001), itself a potent source of influence.

In what follows, we will assume the model of Figure 1 but illustrate it specifically in the context of campaigns and social communication about adolescent marijuana use. We will assume exposure to a campaign's message while remaining cognizant of the difficulty and expense of achieving acceptable levels of exposure.

\section{Thoughts about the campaign}

If the campaign's messages reach the target audience and engage its members cognitively, they will generate positive and negative thoughts in response (Petty \& Cacioppo, 1986). Two important factors are generally expected to be responsible for whether the thoughts are negative or positive: argument strength and biased processing. The arguments used in the campaign's messages will be either stronger or weaker depending on the topic of the campaign, the available lines of persuasion, and the artfulness of the campaign's designers. By definition, strong arguments are those that generate more favorable than unfavorable thoughts; the opposite is true for weaker arguments (Petty \& Cacioppo; Wood, Kallgren, \& Priesler, 1985). Thus, one can expect that stronger arguments will activate fewer contrary cognitions and more supportive ones. Biased processing refers to prior attitudes and dispositions of receivers in the target audience leading them to favor (or oppose) claims in messages before centrally processing the message (Petty \& Cacioppo). Biased processing leads to a tendency to counterargue messages that are counterattitudinal and to support messages that agree with prior attitudes and other dispositions.

ELM posits that the degree to which receivers elaborate messages has an impact on its persuasiveness (Petty \& Cacioppo, 1986). Personal involvement is an important determinant of degree of elaboration; this is the juncture where argument strength and biased processing intersect. When message receivers are highly 
involved, that is, when the topic is of personal relevance, messages are more likely to be centrally processed (Petty, Cacioppo, \& Schumann, 1983; Petty \& Priester, 1994). When receivers are engaged in extensive elaboration or issue-relevant thinking, there is in turn increased scrutiny of argument quality. Empirical evidence shows that as involvement increases, argument quality becomes a more important determinant of attitudes after exposure to a message (Burnkrant \& Unnava, 1989; Petty \& Cacioppo, 1979). High involvement, unlike low, is significantly affected by argument quality; highly involved respondents are more persuaded by strong rather than weak arguments (Petty, Cacioppo, \& Goldman, 1981). Weak arguments presented to those whose prior attitudes are opposed and whose behaviors are being attacked will motivate counterarguing.

In the context of marijuana use and antidrug ads directed at adolescents, the arguments typically made are relatively weak and produce a substantial amount of mental counterargument by biased processors, specifically those who are more at risk to try marijuana. Numerous studies have found that higher age (Monitoring the Future, 2004), sensation seeking (SS), and associations with deviant peers are the three risk factors consistently associated with adolescent drug use. These factors signal stronger personal involvement with antimarijuana messages.

SS (Zuckerman, 1994) is an individual personality trait referring to a motivation for thrill seeking; a need for varied, novel, emotionally intense experiences (Palmgreen, Donohew, \& Harrington, 2001); and a willingness to take risks to achieve those experiences (Zuckerman). High-sensation seekers (HSS) tend to be more impulsive, thrill seeking, dominant, antisocial, and nonconformist (Kipnis \& Wagner, 1967; Zuckerman \& Link, 1968). More importantly, SS has been found to be a moderate to strong predictor of both early onset and regular use of illicit drugs (Hornik et al., 2001; Newcomb \& McGee, 1991; Palmgreen et al., 2001).

The behaviors and attitudes of adolescents at risk for drug use (e.g., HSS) may lead them to be biased in favor of promarijuana and against antimarijuana messages. They are likely to be biased processors when it comes to messages that suggest avoiding drug use. Even when the antimarijuana messages are stronger ones and therefore more difficult to counterargue, they are in absolute terms not nearly as strong as the arguments that can be made about the abuse of legal drugs such as alcohol. The consequence is that biased processors can generate negative thoughts even in the face of stronger arguments about marijuana use. Experimental evidence exists that suggest HSS and low-sensation seekers process messages differently. Stephenson and Palmgreen (2001) found a strong positive association between high SS and perceived personal involvement with marijuana. Greater personal involvement with marijuana was associated with a decrease in general cognitive processing and an increase in negative processing of antimarijuana messages. By thinking less about or by disagreeing more with the message content than low-sensation seekers, HSS reinforce their promarijuana attitudes.

But will biased processors communicate these negative thoughts in a social communication situation? After all, marijuana use, while widespread among older 
adolescents, is still practiced only by a minority. The majority of young people are not users. For instance, only $16 \%$ of 8 th graders and $35 \%$ of tenth graders ever used marijuana in 2004 (Johnston, O’Malley, Bachman \& Schulenberg, 2004).

\section{Factors affecting expression of thoughts}

Social communication in response to communication campaigns has been the object of a substantial amount of research summarized in both the scientific literature (Weimann, 1994) and the popular (Rosen, 2000). Who seizes on the topics and messages circulating in the mass-mediated environment for resending to others is at the heart of research on opinion leadership. A few of the factors associated with social communication from such sources include people who are involved, knowledgeable, interested, gregarious, and socially well connected (Weimann). We will focus on a few of the many factors involved: (a) Individual differences in expressiveness, (b) the communicator's perception of whether his or her opinion is in the majority or minority, and (c) the accuracy of that opinion.

\section{Individual Differences in Expressiveness}

Whether people are willing to express their positive and negative thoughts depend in part on personality characteristics. Extraversion, gregariousness, and centrality in a communication network are among the many individual characteristics that could be associated with greater or lesser likelihood of social communication about a campaign. Of special interest, however, is when a personality characteristic associated with more social communication is also associated with holding a particular class of thoughts. SS is just such a characteristic in the context of drug use.

We have already argued that HSS and low-sensation seekers differ in their attitudes toward drug use and in the likelihood of trying and using illicit substances. HSS and low-sensation seekers also differ in their interaction style when discussing issues with attitudinally similar or dissimilar strangers (Williams \& Ryckman, 1984). HSS are more talkative and assertive compared to low-sensation seekers under the same conditions. They also interact more with dissimilar others and are more willing to express their opinions directly even when expressing disagreement to a dissimilar other. Zuckerman and Link (1968) find that HSS need others primarily as an audience to their performance; therefore, they tend to dominate discussions. Further, correlational evidence suggests that prodrug interactions, associations with deviant peers, and SS are all significant predictors of intention to use marijuana (Yanovitzky, 2005).

\section{Perception of Majority and Minority Opinion and Accuracy of Perception}

The need to hold correct opinions underlies a number of theories of human behavior. Research on the Asch conformity paradigm (Asch, 1951; Tanford \& Penrod, 1984; Turner, 1991), attitude change (Eagley \& Chaiken, 1993; Petty \& Cacioppo, 1986), and social comparison (Schachter, 1951) all assume that people need to hold 
correct opinions in ambiguous and sometimes even not-so-ambiguous (Asch, 1956, 1966) contexts. The perception that one's social group holds a clear opinion can silence communication that seems to counter that majority opinion, even if the perception is incorrect.

If a majority in a group context remains silent in the presence of a vocal minority, then public expressions of the majority opinion will be reduced (Noelle-Neumann, $1973,1984,1991)$. When there is a misperception by the majority of a group's opinion about an issue, members' willingness to express their own views, assumed to be at odds with the majority norm, will be depressed. In the case of a communication campaign, a majority in favor of the campaign's message will remain silent in the face of contrary opinion if they sense incorrectly that they are in the minority. When those with a minority view are vocal about their views in a group communication context, their minority views may be incorrectly perceived to be those of the majority, silencing the true majority. The result will be influence in the group from a minority position, perhaps a position held by an expressive subgroup ready and able to counterargue a mainstream message.

Research on small groups and group decision making suggests that there are circumstances when opinion minorities successfully exert influence on majorities (Wood, Lundgren, Ovellette, Busceme \& Blackstone, 1994). We argue that group communication among adolescents about risky deviant behaviors such as marijuana use is a situation where the true opinion minority-those who view drug use as a desirable behavior - can exert strong influence on the majority. This is especially likely in this case because data from nationally representative samples suggest that adolescents overestimate the percentage of their peers who use marijuana, thereby assuming that the majority use, while in fact a minority use. It has been reported that teenagers believe over $70 \%$ of their peers smoke "weed," when more than half of teenagers (56\%) report never having tried marijuana (Partnership for a Drug-Free America, 2000).

The confluence of these factors increases the likelihood of negative comments about antidrug messages among adolescents: overestimates by adolescents of marijuana use by their peers, a tendency for those most biased against antidrug messages (high SS) to be most expressive in social contexts, and the possibility that the true majority is less communicative and more likely to incorrectly believe it is in the minority.

Effects of expressed opinions on beliefs in a group context

In social groups, the effects of existing opinion on the groups' beliefs will depend in part on what opinions are expressed, by whom, and with what persuasive strength. The possibility of both silent majorities and silent minorities exists. Majority opinion often determines group opinion because those who deviate from the majority (i.e., a minority group or member) will be silenced in the presence of a dominant majority (Festinger, Schachter, \& Bach, 1950; Moscovici, 1985; Schachter, 1951; Wood, Lundgren, Ouellette, Busceme, \& Blackstone, 1994). Majorities have a 
greater ability to exert influence, and their greater numbers normally indicate a greater ability to resist influence (Latane \& Wolf, 1981; Tanford \& Penrod, 1984).

Communication with deviant minorities within the group is necessary for the group to achieve consensus, and generally, members of the majority respond negatively to minorities (Levine, 1989). In most group decision-making tasks, minorities exert little, if any, influence on the majority unless their opposing views have the credibility of higher status. ${ }^{2}$ For example, in adolescent groups, older teens will generally have higher social status than younger ones, and more likely some experience with marijuana trial or use, or at least less negative attitudes than younger teens. This higher status puts older adolescents in an "opinion leader" position, imparting greater authority on their attitudes pertaining to drug use.

Self-categorization theory holds that the perceived similarity between the source and the target is a strong basis for occurrence of minority influence (David \& Turner, 1996; Turner, 1991). Given this condition, others are influential only to the extent that they are seen as similar to oneself on dimensions relevant to the topic. Agreement with similar others reduces uncertainty, and disagreement is often resolved through judgment change or cognitive restructuring (Wood et al., 1994). Thus, minority influence is possible when the minority members are perceived by the majority as in-group members.

People categorize themselves as members of positively valued social groups to achieve a favorable self-identity (Tajfel, 1981; Turner, 1991). This is of particular relevance for adolescents because they are concerned about issues of identity formation. Identities derive in part from surveying one's social groups and deciding with whom to align (Lavoie, 1994). Generally, when people choose to identify with valued groups, they adopt the salient attributes of that group, including attitudes and beliefs of group members (Pool, Wood, \& Leck, 1998; Tajfel).

These conditions are relevant to social interactions about deviant behaviors among adolescents. Younger (and consequently less risky) adolescents readily identify with their older, more outgoing, and sometimes more risky counterparts. This eagerness to self-identify with older (i.e., cooler) individuals makes them more susceptible to social influence as a result of normative pressures originating from social groups they may wish to emulate.

In a group of dissimilar adolescents, minority influence can occur as a result of this confluence of conditions within the members of the group. Namely, that (a) the group seeks to find some opinion agreement, (b) the opinion minorities hold special competence or status, and (c) the majority perceives the minority either as similar to themselves or as part of a favorably viewed social group.

In sum, extant theories of social influence and opinion leadership in the context of public communication campaigns need to be extended to include the possibility that messages in a public campaign may circulate in a way deleterious to the campaign's goals. Audience members may counterargue weak messages and communicate with others about those messages, beginning the circulation of information 
counter to the campaign's agenda. In group communication contexts and to lesser extent social contexts in general, the perception of majority and minority opinion is determined in part by the opinions expressed and heard. When opinions counter to the majority dominate expression, then the majority opinion is silenced, leading to increased circulation of the minority's contrary views.

Extending the theory of social influence from communication campaigns to conditions of possible iatrogenic consequences can be an important addition to understanding the development of public opinion, campaign effects, and other forms of mass influence. Our study is a specific application of this theory to adolescent drug attitudes in an intranet chat situation after exposure to antidrug marijuana ads. We want to understand how adolescents talk to each other about marijuana use after viewing antimarijuana televisions ads. We believe that individual differences in SS and risk of regular marijuana use will affect whether the discussions will generate mostly favorable or unfavorable comments about marijuana use. In addition, message argument strength is manipulated so that some subjects view weak-argument ads and some view strong-argument ads.

In the test that follows, evidence pertinent to portions of the model presented in Figure 1 will be offered. Specifically, we will test the impact of antimarijuana ads on two groups: those who receive the ads without any discussion with others and those who receive the ads with the opportunity to discuss with a diverse group of peers. Groups receiving strong and weak ads will be compared to assess the impact of strong ads on negative and positive responses. We will test the following hypotheses:

H1: High SS (high risk) adolescents will have more favorable attitudes toward marijuana and stronger intentions to use.

H2: High SS adolescents will communicate more to their peers in group chat situation.

H3: Groups that discuss antidrug ads will have more promarijuana attitudes and intentions than groups that do not.

R1: How will the opportunity for discussion and the strength of ads discussed interact? Will exposure to strong antidrug arguments reduce the deleterious effects of discussion in comparison to weak arguments?

\section{Method}

Data were gathered in November 2002 from three schools in the metropolitan Philadelphia area. The sample comprised 535 seventh- and twelfth-grade students. They were recruited through their teachers at school to be subjects in a study of media advertising about healthy behavior. Schools were compensated for participation by their students. All students were required to provide parental consent and to give their own informed assent to participate. 
Of the participants, $245(46 \%)$ were male and the mean age was 15.5 years (SD 1.7 years). ${ }^{3}$ There were 262 (49\%) African Americans, 106 (20\%) Asians, 102 (19\%) Caucasians, and $60(11 \%)$ students of other ethnic or racial groups. ${ }^{4}$

\section{Research design}

Two factors were crossed resulting in four treatment groups in a between-subjects post-only experimental design. The first factor was chat, an online chat among a small group of between 4 and 10 participants. The second factor was the judged effectiveness of antidrug ads, strong and weak. We thus have four conditions: (a) chat and strong argument, (b) chat and weak argument, (c) no chat and strong argument, and (d) no chat and weak argument. Those in the chat conditions engaged in online discussions. The study design is outlined in Figure 2 below, illustrating subjects nested within groups and groups nested within conditions. There were between 119 and 141 subjects in each condition and 66 chat groups.

\section{Procedures}

Participants came to the room designated for use in our experiment in groups of 10 20. Each student sat at a laptop computer set up to run the experiment on MediaLab software (Jarvis, 1988) that allows on-screen questionnaires as well as integration with video playback. At each session, students were randomly assigned to the strong- or weak-ad exposures in the chat or no-chat conditions. At any one session, it was not possible to have some students in the chat and some in the no-chat condition because of the way the online discussions took place. All the computers were linked through a local intranet. One half of the computers allowed communication among participants in the strong-ad condition; the other half allowed communication among participants in the weak-ad condition. In the chat condition, students interacted with one another after seeing the ads and before filling out the outcome measures.

Participants were instructed not to talk during the time they were supposed to be discussing online. The chat room itself was enabled by a program called mIRC (Internet Relay Chat Program) that allowed subjects to use a nickname rather than their own name to maintain anonymity while interacting with other members of their group. The content of the chats was captured in electronic files by the nickname

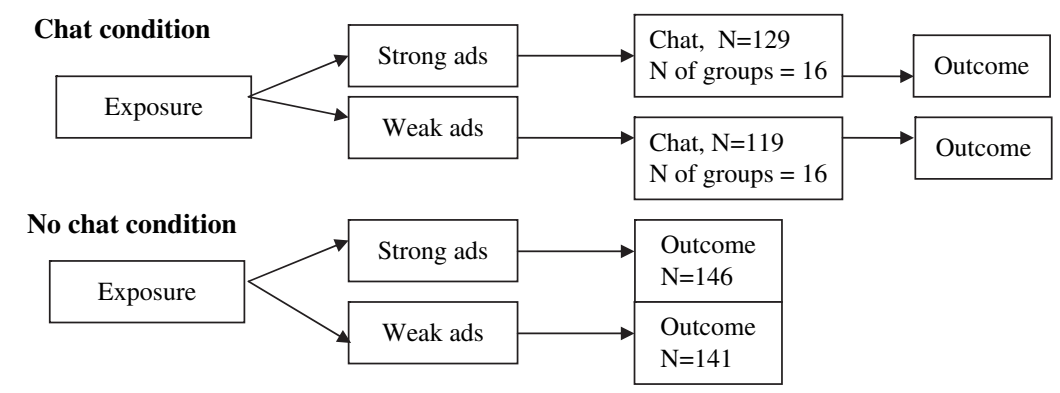

Figure 2 Study design. 
assigned to the student, which in turn were linked back to the students' names and their data files.

\section{Advertising content}

Each ad condition used five antimarijuana ads embedded within an edited control video. The five strong ads and the five weak ads were the same ones used in a previous study testing the effectiveness of ads in producing belief change and priming changes in intention to use and attitude toward using marijuana regularly. ${ }^{5}$ The content of the strong and weak ads is roughly parallel. In each group, three of the ads cite a negative consequence of marijuana use, while the other two are more general. In the weak condition, the two ads admonished young people to "say no to drugs," while in the strong condition, the other two ads concerned building esteem (e.g., refusing drugs makes one stronger).

\section{Outcome measures}

Intention to use marijuana was assessed by asking students how likely it is that they would use marijuana even once or twice in the next month (trial use) and how likely it is that they would use marijuana nearly every month in the next 12 months (regular use). Responses to both items were measured on 4-point scales with end points I definitely will not to I definitely will. Intention for trial and regular use were combined into one 4-point intention index with categories definitely will not try, definitely will not use regularly, probably will not use regularly, and probably or definitely will use regularly.

Attitude was assessed by using three 7-point semantic differential items. The stem "Your using marijuana nearly every month for the next 12 months" precedes the scales bad-good, dumb-smart, and unpleasant-pleasant. The mean of the three items was taken to create a single measure for attitude toward personally using marijuana ranging from +3 (extremely good, smart, pleasant) to $-3(\alpha \quad .88, M$ $-2.13, S D \quad 1.3)$.

Several belief items were used to assess overall positive and negative beliefs about marijuana use. The question stem was "How likely is it that the following would happen to you if you used marijuana nearly every month for the next 12 months?" followed by 14 outcomes. Examples of negative beliefs are that marijuana use will damage the brain, lead to loss of ambition, and will mess up their lives. Positive beliefs included "have a good time," "be more creative and imaginative," and "have a good time with friends." very unlikely to very likely. The belief-based estimate of attitude was created by reversing the scoring of positive items and taking the mean of all 14 items ( $\alpha$ $.87, M \quad .23, S D \quad .9$ ). The belief measure is coded such that higher scores indicate unfavorable attitudes toward regular marijuana use.

Two sets of question items were combined to construct a normative belief-based estimate of the subjective norm. Subjects were first asked on a 5-point response scale ranging from strongly disagree to strongly agree if they want to do what each of their 
relevant others want them to do. This represents the participant's motivation to comply with each of their relevant others, close friends, parents/caregivers, teachers, and most people their age. Four corresponding normative beliefs were then asked with the question "How do you think your [relevant other] would feel about you using marijuana nearly every month for the next 12 months?" Products were computed between motivation to comply and normative belief for each relevant other, and these products were then combined into a single belief-based subjective norm measure by taking the mean. The final scale ranges from -10 indicating the relevant other strongly disapproves of use and the subject is highly motivated to comply, to

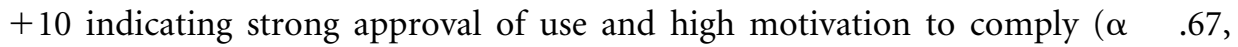
$M \quad-3.25, S D \quad 2.5)$.

Several questions about belonging to a social group were asked. These are not normally a part of IMBC. These are meant to capture the subject's beliefs about being accepted by peers or friends if he or she says no to marijuana. The question stem is, "If friends offered you drugs and you said no," followed by four beliefs. There are two positive consequence beliefs, "my friends would accept me and my decision" and "my friends would respect me." And two negative consequence beliefs, "my friends would think I wasn't cool" and "I would feel left out." The response scale ranged from strongly disagree $(-2)$ to strongly agree $(+2)$. The complete scale has an alpha of .52.

The measure of SS is a composite of four items asking subjects whether they like to explore strange places, do frightening things, have new and exciting experiences, and prefer friends who are exciting and unpredictable. The response scale has 5 points ranging from strongly disagree to strongly agree. The complete measure has an alpha of .6 and a mean of $3\left(\begin{array}{ll}S D & .8\end{array}\right)$.

A risk measure is used in most of the following analyses as a covariate or control. A weighted measure of each subject's "last year's risk of marijuana use" is calculated from their age, SS, whether their friends use, and whether they have been offered marijuana (Yzer, Cappella, Fishbein, Hornik, \& Ahern, 2003).

\section{Chat content-coding procedure}

All electronic transcripts from the discussions were coded by four trained undergraduate coders. A comment was defined as a complete text entry by an individual ended by a hard return on their keyboards. The length of comments varies from one word to several sentences, and a single comment may have zero or multiple codable events. Average intercoder reliability among all four coders was computed yielding a Cohen's kappa of .8 .

Two general types of comments were prevalent in the discussions, those pertaining to the ad stimuli and its subject matter (i.e., marijuana and more broadly drugs and other risky behaviors) and comments about other people (either in the discussion group or outside the discussion group). The first category includes talk about ad content and features, marijuana, other kinds of controlled substances, and other risky behaviors such as alcohol consumption or sexual activity. Valence is coded so that positive comments are expressions of approval or liking for the ads and 
negative comments are expressions of disapproval or disliking. Comments that are disapproving of drug-use and other risky behaviors are coded as positive (e.g., Smoking pot is as bad for your lungs as cigarettes). Those that were approving of drug-use and risky behaviors were coded as negative (e.g., The ads won't stop anyone from doing drugs).

The second category pertains to comments made about others, for example, in the discussion group and authority figures such as teachers or parents. Comments were coded for negative or positive valence. Negative comments are unsupportive of or disapproving of others (e.g., Mr. Snyder the math teacher sucks), and positive comments are supportive of or approving of others (e.g., You guys are smart). Comments that did not fall into the two categories and those that are not valenced or were neutral were not included in the analyses.

\section{Analysis of outcomes}

Individual-level general linear model (GLM) procedures are used to test chat and ad argument strength effects in most cases. However, in the chat condition, participants are expected to influence one another's responses. Statistically, the influence of one person's score on another's score is a violation of the independence assumption, an important assumption for accurate statistical inference. Nonindependence of outcome variables, when detected, requires analysis at the group level (Kashy \& Kenny, 2000). Intraclass correlations are obtained for each outcome variable in the chat condition. In the following section, results will be presented at the individual level as if there is no clustering within groups. Group-level results will be referenced for outcome variables that exhibit significant nonindependence. ${ }^{7}$

\section{Results}

Descriptive analyses

Means, standard deviations, and correlations among key outcome variables and SS are presented in Table 1. Participants generally have a negative attitude toward

Table 1 Correlations and Descriptive Statistics for Key Outcome Variables

\begin{tabular}{llllllr}
\hline Outcomes & 1 & 2 & 3 & 4 & 5 & 6 \\
\hline 1. Beliefs & & & & & & \\
2. Attitude & $.46^{*}$ & & & & & \\
3. Intention & $.4^{*}$ & $.6^{*}$ & & & & \\
4. Belong & .06 & .08 & .04 & & & \\
5. Subjective norm & $.3^{*}$ & $.47^{*}$ & $.12^{\star}$ & $.12^{*}$ & & \\
6. Sensation seeking & $.10^{*}$ & $.26^{*}$ & $.24^{*}$ & .03 & $.2^{*}$ & \\
$M$ & .38 & 2.13 & 1.54 & .94 & 3.32 & 2.99 \\
$S D$ & .9 & 1.3 & 1 & .8 & 2.5 & .79 \\
\hline
\end{tabular}

${ }^{\star} p \leq .05$. 
marijuana use and believe that negative consequences of regular use are likely and positive consequences are unlikely. Furthermore, they perceive that relevant others would disapprove if they used marijuana regularly. By and large, the subjects have a low intention of using marijuana on a regular basis. Hypothesis 1 is supported by the correlations, evidencing that sensation seekers have positive attitudes toward marijuana and greater reported intentions to use. Except for the belong scale, all the outcome variables are significantly associated with SS.

The effects of chat, ad argument strength, and their interaction were tested via a GLM, with risk as a covariate predicting behavioral beliefs, attitude, social normative disapproval, intention, and belonging. The test of the main effect of discussing antimarijuana ads with others is statistically significant, $F(5,520) \quad 3.18, p \quad .008$, Wilks' lambda .97. We find no effects for ad argument strength, $F(5,520) \quad 0.61$, p .69, Wilks' lambda .99, or for the interaction between chat and ad argument strength, $F(5,520) \quad 0.49, p \quad .79$, Wilks' lambda $\quad 1$. Raw means of all relevant outcome variables by experimental condition are presented in Table 2.

\section{Effect of chat $^{8}$}

The main effects of chat are due primarily to social normative considerations. No significant chat effects are found for intention to use marijuana, $F(1,524) \quad .1 .89, p$ .17. The direct, $F(1,524) \quad 3.45, p \quad .06$, and indirect, $F(1,524) \quad 3.43, p \quad .07$, measures of attitude yield marginally significant results. Recall that the belief measure is coded such that higher scores indicate unfavorable attitudes toward regular marijuana use. Those who discussed the antimarijuana ads with others reported depressed antimarijuana beliefs (chat condition, $M \quad .3, S E \quad .06$; no-chat condition, $M \quad .44, S E \quad .05)$. A consistent pattern is found for attitudes such that those who discussed reported elevated promarijuana attitudes (chat condition, $M-2.02$, $S E \quad .08$; no-chat condition, $M \quad-2.21, S E \quad .07)$ than those who did not discuss. Moreover, participants in the chat conditions report feeling significantly greater promarijuana normative pressure $\left(\begin{array}{lll}M & -2.93, S E & .15\end{array}\right)$ than those in the no-chat condition, $M \quad-3.64, S E \quad .14, F(1,524) \quad 11.67, p \quad .001$. The belonging scale was also affected by discussing, $F(1,524) \quad 4.81, p \quad .03$. Those who chatted $(M \quad-.86$, $S E \quad .05)$ are more likely to perceive that they will be ostracized by their peers if they say no to using marijuana than those who did not chat $\left(\begin{array}{lll}M & -1.01, S E & .05\end{array}\right){ }^{9}$

A second GLM was estimated predicting only the subcomponents of social normative disapproval (i.e., peers and authority figures). This is done in order to explore the effects of chat on social normative pressure by isolating the components that might be contributing most to the effect. Social normative disapproval from peers and authority figures are predicted by chat, with risk as a covariate. The effect for authorities is statistically significant, $F(1,526) \quad 13.7, p<.0001$, while the effect for peers is not, $F(1,526) \quad 3.2, p \quad .07$. Those who chatted expected less perceived disapproval of marijuana use from authority figures $\left(\begin{array}{lll}M & -4.62, S E & .2\end{array}\right)$ than those who did not chat $\left(\begin{array}{lll}M & -5.65, S E & .19\end{array}\right)$. 


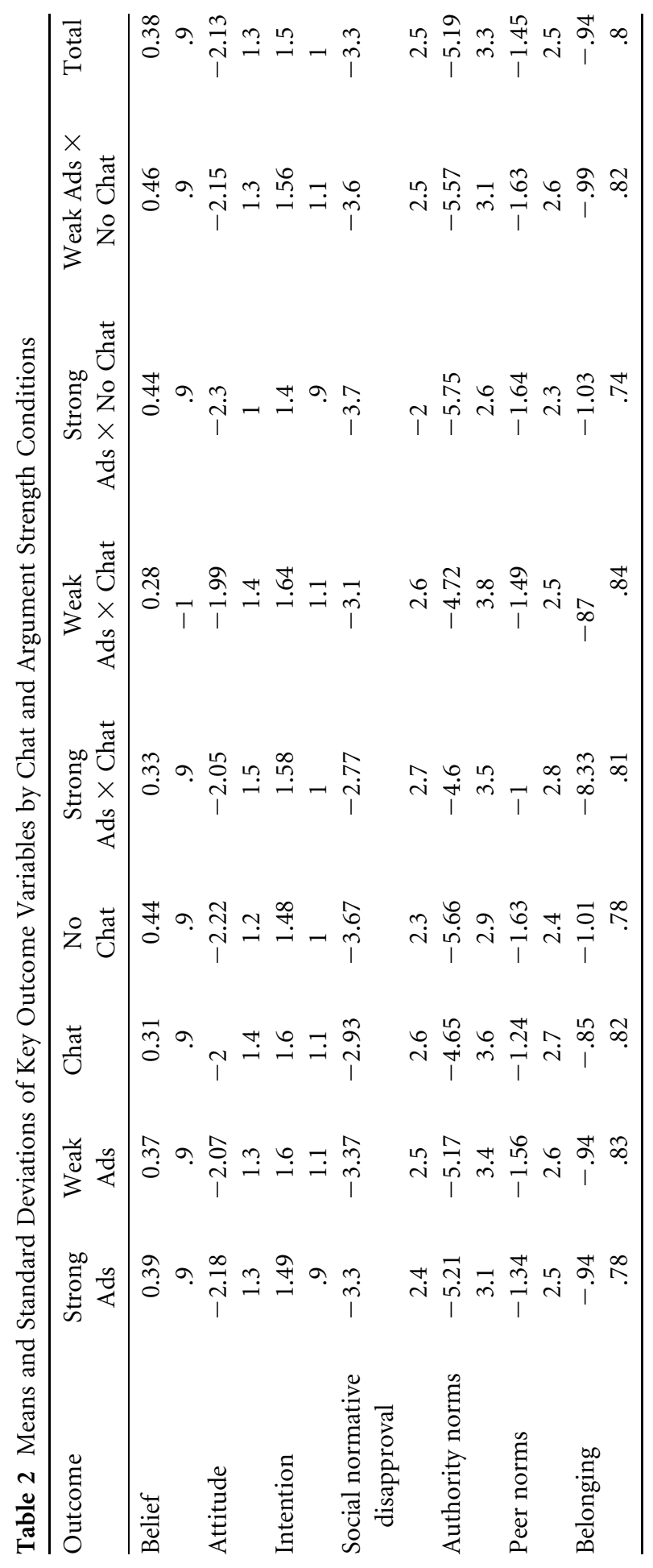


Table 3 Mean Comments Said per Person by Three Way Split on Outcomes in Chat Condition

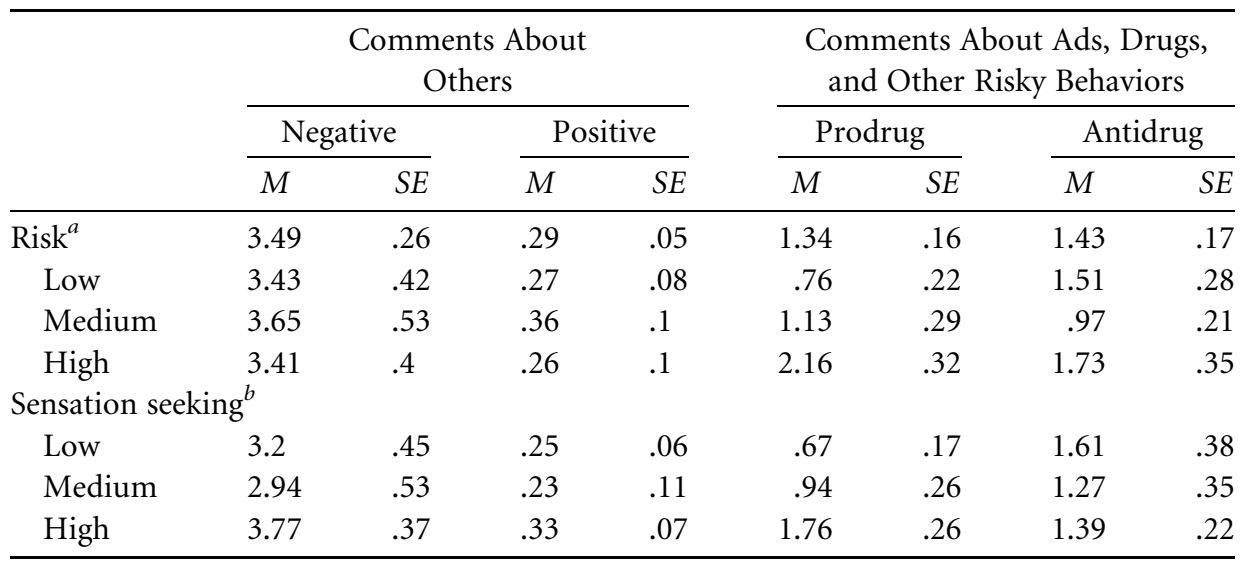

Note: Significance tests conducted through one way analysis of variance, $F$ values are dis cussed in text.

${ }^{a}$ Low, $n=93$; medium, $n=69$; high, $n=82$.

${ }^{b}$ Low, $n=64$; medium, $n=48$; high, $n=135$.

\section{Content analyses}

The content analysis codes allow us to look at the types of adolescents who dominate the discussions and the valence of their utterances with regard to drug-use behaviors. Associations between the predictors and the coding categories were tested through bivariate correlations. Three-category mean difference tests were also conducted to detect nonlinear effects if any. Table 3 shows means and standard errors of the four types of comments that were coded by risk status and SS (low, medium, and high). ${ }^{10}$ We investigate the effect of risk status on participation in the discussions because it is an indicator of strong personal relevance regarding marijuana use. ${ }^{11}$ There is generally a high prevalence of negative talk about others, that is, derogatory remarks about other people either within or outside the group. Talk about ads, drugs, and other risky behaviors was low compared to talk about others, but there were significant differences in the kinds of drug-related talk between high and low risk. Those who are at a higher risk of using marijuana utter significantly more prodrug comments than those who are at low risk, $r \quad .24, p<.0005, F(2,243)$ $7.23, p \quad .001$. Similarly, HSS tend to make more prodrug commentary than lowsensation seekers, $r \quad .23, p<.0005, F(2,244) \quad 4.86, p \quad .01$. High SS groups $(r$ $.15, p \quad .02)$ also tend to make more derogatory comments about other people in the context of these online discussions. In contrast, antidrug comments as well as positive comments about other people are not associated with either predictor.

Do these factors influence total talking? We test this by adding up all the four comment categories and correlating this with risk and SS. High SS subjects say more $\left(\begin{array}{llll}M & 7.25, S E & .6, n & 135\end{array}\right)$ than do medium SS ( $\left.M \quad 5.38, S E \quad .8, n \quad 48\right)$ and low SS $\left(\begin{array}{llll}M & 5.73, S E & .7, n & 64\end{array}\right)\left(\begin{array}{lll}r & .21, p & .001\end{array}\right)$. Raw means suggest high-risk 
individuals say more $(M \quad 7.56, S E \quad .67, n \quad 82)$ than do those medium $\left(\begin{array}{lll}M & 6.12 \text {, }\end{array}\right.$ SE $\quad .8, n \quad 69)$ or low risk ( $M \quad 5.97, S E \quad .6, n \quad 93)$, but tests indicate that these differences are not statistically significant, $r \quad .11, p \quad .08, F(2,241) \quad 1.72, p \quad .18$. Results suggest that high SS individuals are more expressive in these conversations, and their contributions to discussion are more likely prodrug than antidrug.

\section{Discussion}

This paper examined the effect of discussion among adolescent peers on the persuasive effects of antimarijuana advertising. Following the general framework proposed in Figure 1, we experimentally predicted exposure to campaign messages, the quality of messages, and subsequent social communication about those messages. Strongand weak-argument ads were used as stimuli, and half of the participants engaged in online group interactions with other adolescents to talk about the ads and their opinions of them before completing the measurement instrument.

Consistent with Hypothesis 1, results of correlation analysis showed that SS is positively associated with more favorable attitudes toward marijuana use. Highsensation seekers reported more promarijuana attitudes and social normative beliefs. Analyses of the chat contents revealed that high-risk and high SS individuals say more in the discussion context and their comments tend to be more favorable toward drug use than those of their low-risk and SS counterparts. As a result of exposure to such talk, those who discussed the ads reported more normative pressure to use marijuana. Interestingly, the negative effect on perceived social norm was stronger for normative pressures from authority figures such as parents and teachers. Consistent with the hypothesized effect, those in the chat conditions reported elevated promarijuana beliefs and attitudes, although these differences were only marginally significant. No significant persuasion advantages were found in those who saw the strong ads compared to those who saw the weak ads. There were also no apparent interaction effects between ad argument strength and chat.

The results of this study support three key claims in the model. First, that individual difference factors influence the likelihood of social communication. Second, that the nature of interpersonal messages communicated is determined in part by the favorable or unfavorable thoughts of people generated through biased or unbiased processing. Finally, that exposure to social interactions about campaign messages can affect factors related to behavioral intentions. In this case, we found that discussion produced significant effects on perceived normative pressure from relevant others.

How do these findings affect media-based antidrug interventions targeted toward adolescents? Our study does not assess how frequently young people discuss drugs or antidrug efforts by the public health community. However, if discussion does occur and especially if adolescent groups naturally gravitate toward similar others (Dishion et al., 1999; Maxwell, 2000), then the potential for deleterious effects is heightened. High-risk adolescents will tend to interact more with each other and 
are therefore more likely to provide positive reactions to talk about deviant behaviors. Negative campaign effects can occur as a result of social diffusion (Hornik \& Yanovitzky, 2003). If antidrug messages encourage discussion among peers, and such discussion in turn leads to negative effects, then a media campaign can result in substantial deleterious effects, perhaps especially among the segment of the population most likely at risk. One of the curious findings in these results is the robust negative effect generated by the discussions on perceived norms regarding authority figures, namely, parents and teachers. Those who chatted are less likely to believe that relevant authority figures would disapprove if they tried marijuana. There were no similar effects on normative beliefs regarding relevant peers. This finding highlights the conclusion reached by Dishion and his colleagues that parent involvement in interventions can be an important determinant of program success. If discussing deviant behaviors among peers diminishes perceived disapproval of parents, perhaps messages that are designed to counteract this effect or those that encourage parent involvement would successfully promote antimarijuana attitudes.

There is a clear need for further research on the conditions of interpersonal influence, especially in situations where there is potential for deleterious campaign effects. We emphasize the importance of looking at individual difference factors as potentially playing conditional roles in determining not only how messages are processed, but also whether interpersonal communication takes place and the direction that social influence will take.

\section{Acknowledgments}

The study was supported by a grant from the National Institute on Drug Abuse (DA 12356-02) to M.F., J.N.C., and R. Hornik. The views expressed are those of the authors alone.

\section{Notes}

1 The IMBC posits that performance of a behavior is preceded by a strong intention to perform that behavior. Intention in turn is determined by attitudes, perceived norms, and self efficacy relevant to the behavior. These three are believed to be a function of outcome, normative, and efficacy beliefs, respectively. The model indicates that successful persuasion that changes relevant beliefs will likely lead to changes in behaviors. The variables identified by the IMBC as predictive of the intention to use marijuana regularly have received substantial support (Fishbein et al., 2002).

2 For example, those who are identified as "experts" or especially knowledgeable about the topic will have higher status even when their opinion is not the same as the majority. Of more import to this paper, higher status can also indicate a general social identification of greater esteem (i.e., older children are of higher status socially than younger children).

3 The bottom and top categories of age were combined "below 11 " and "above 18" coded as 10 and 19 years, respectively, to calculate the mean and standard deviation. 
4 The high percentage of African American students is consistent with the public school populations in the Philadelphia metropolitan area.

5 In previous research testing ad effectiveness among adolescents, the five stronger ads had higher scores on a 4 item measure of perceived effectiveness than did the weak ads. Compared to the weaker ads, the stronger ads also produced a greater decrease in promarijuana attitudes and greater perceived disapproval from significant adult groups especially for high risk youth (Barrett, Ahern, Yzer, Cappella, \& Fishbein, 2004).

6 Complete list of beliefs available from the authors upon request.

7 Intraclass correlations, a measure of the degree of data clustering among subjects within groups in the chat condition, are small but significant for the indirect estimate of attitude, $r=.07, F(62,467)=1.48, p=.01$, and the indirect estimate of the subjective norm, $r=.05, F(62,467)=1.334, p=.05$, scales. Tests for treatment effects on these latter two measures are discussed both at the group and at the individual level (Kashy \& Kenny, 2000).

8 Means reported in the text are adjusted means outputs from GLM procedure, with risk as a covariate.

9 Another set of GLM procedures is run separately for subjective norm since it shows significant clustering by group. The following procedures test for chat and ad type effects on the subjective norm measure, with risk as a covariate. There remains a significant chat effect, $F(1,69)=11.19, p=.001$, with the adjusted means indicating groups in the chat condition $(M=2.9)$ think their relevant others are less disapproving of marijuana use than those in the no chat condition $(M=3.6)$. No ad strength or interaction effects between chat and ad strength were found.

10 SS and risk were split along the 33rd and 66th percentile, yielding variables with "low" (1), "medium" (2), and "high" (3) categories.

11 Although the variables comprising the risk measure include SS, the correlation between them is moderate $(r=.23, p<.0005)$. Therefore, while there is some overlap between the two measures, risk status represents a substantially different aspect of personal relevance (or marijuana use) from SS.

\section{References}

Asch, S. E. (1951). Effects of group pressure upon the modification and distortion of judgment. In H. Guetzkow (Ed.), Groups, leadership, and men (pp. 177 190). Pittsburgh, PA: Carnegie Press.

Asch, S. E. (1956). Studies of independence and conformity: A minority of one against a unanimous majority. Psychological Monographs, 70(Whole No. 416).

Asch, S. E. (1966). Opinions and social pressure. In A. P. Hare, E. F. Borgatta, \& R. F. Bales (Eds.), Small groups: Studies in social interaction (pp. 318 324). New York: Alfred A. Knopf.

Barrett, D., Ahern, K., Yzer, M., Cappella, J., \& Fishbein, M. (2004). Measuring the effectiveness of anti drug public service announcements. Paper presented at the annual conference of the International Communication Association, New Orleans, LA.

Burnkrant, R., \& Unnava, R. (1989). Self referencing: A strategy for increasing processing of message content. Personality and Social Psychology Bulletin, 15, 628638. 
Cialdini, R. B. (2001). Influence: Science and practice (4th ed.). Boston: Allyn \& Bacon.

David, B., \& Turner, J. C. (1996). Studies in self categorization and minority conversion: Is being a member of the out group an advantage? British Journal of Social Psychology, 35(1), 179199.

Dishion, T., \& Andrews, D. (1995). Preventing escalation in problem behaviors with high risk young adolescents: Immediate and one year outcomes. Journal of Consulting and Clinical Psychology, 63, 538548.

Dishion, T., McCord, J., \& Poulin, F. (1999). When interventions harm: Peer groups and problem behavior. American Psychologist, 54, 755764.

Dishion, T., Poulin, F., \& Burraston, B. (2001). Peer group dynamics associated with iatrogenic effects in group interventions with high risk young adolescents. In D. Nangle \& C. Erdley (Eds.), The role of friendship in psychological adjustment (pp. 79 92). San Francisco: Jossey Bass.

Eagley, A., \& Chaiken, S. (1993). The psychology of attitudes. Fort Worth, TX: Harcourt Brace Jovanovich.

Festinger, L., Schachter, S., \& Bach, K. (1950). Social pressures on informal groups. New York: Harper and Row.

Fishbein, M., Cappella, J. N., Hornik, R., Sayeed, S., Yzer, M., \& Ahern, R. K. (2002). The role of theory in developing effective anti drug public service announcements. In W. Crano \& M. Burgoon (Eds.), Mass media and drug prevention: Classic and contemporary theories and research (pp. 89 118). Mahwah, NJ: Lawrence Erlbaum.

Foxcroft, D. R., Lister Sharp, D., \& Lowe, G. (1997). Alcohol misuse prevention for young people: A systematic review reveals methodological concerns and lack of reliable evidence of effectiveness. Addiction, 92, 531537.

Greenwald, A. G. (1968). Cognitive learning, cognitive response to persuasion, and attitude change. In A. G. Greenwald, T. C. Brock, \& T. M. Ostrom (Eds.), Psychological foundations of attitudes (pp. 147 170). San Diego, CA: Academic Press.

Hornik, R., Maklan, D., Judkins, D., Cadell, D., Yanovitzky, I., Zador, P, et al. 2001). Evaluation of the national youth anti drug media campaign: Second semi annual report of findings. Rockville, MD: Westat.

Hornik, R., \& Yanovitzky, I. (2003). Using theory to design evaluations of communication campaigns: The case of the National Youth Anti Drug Media Campaign. Communication Theory, 13, 204224.

Jarvis, B. (1988). MediaLab Research Software (Version 3.0) [Computer software]. New York: Empirisoft.

Johnston, L., O'Malley, P., Bachman, J., \& Schulenberg, J. (2004). Monitoring the future: National survey results on drug use, 19752003 (Vol. 2). Bethesda, MD: University of Michigan Institute for Social Research and National Institute on Drug Abuse.

Kashy, D., \& Kenny, D. (2000). The analysis of data from dyads and groups. In H. Reis \& C. Judd (Eds.), Handbook of research methods in social and personality psychology (pp. 451 477). New York: Cambridge University Press.

Katz, E., \& Lazarsfeld, P. (1955). Personal influence. New York: Free Press.

Kipnis, D., \& Wagner, W. (1967). Character structure and response to leadership power. Journal of Experimental Research in Personality, 2, 1624.

Latane, B., \& Wolf, S. (1981). The social impact of majorities and minorities. Psychological Review, 88, 438453. 
Lavoie, J. C. (1994). Identity in adolescence: Issues of theory, structure, and transition. Journal of Adolescence, 17(1), 1728.

Levine, J. M. (1989). Reaction to opinion deviance in small groups. In P. Paulus (Ed.), Psychology of group influence (2nd ed.) (pp. 187 231). Hillsdale, NJ: Lawrence Erlbaum.

Maxwell, K. (2000). Do friends matter?: The role of peer influence on adolescent risk behavior. Unpublished doctoral dissertation, Annenberg School for Communication, University of Pennsylvania, Philadelphia, PA.

Moscovici, S. (1985). Social influence and conformity. In G. Lindzey \& E. Aronson (Eds.), The handbook of social psychology (Vol. 2, 3rd ed., pp. 347 412). New York: Random House.

Newcomb, M., \& McGee, L. (1991). Influence of sensation seeking on general deviance and specific problem behaviors from adolescence to young adulthood. Journal of Personality and Social Psychology, 61, 614628.

Noelle Neumann, E. (1973). Return to the concept of powerful mass media. Studies in Broadcasting, 9, 67112.

Noelle Neumann, E. (1984) The spiral of silence: Public opinion Our social skin. Chicago: University of Chicago.

Noelle Neumann, E. (1991). The theory of public opinion: The concept of the spiral of silence. In J. Anderson (Ed.), Communication yearbook 14 (pp. 256 287). Newbury Park, CA: Sage.

Palmgreen, P., Donohew, L., \& Harrington, N. (2001). Sensation seeking in anti drug campaign and message design. In R. E. Rice \& C. K. Atkins (Eds.), Public communication campaigns: Theory, practice and effects (pp. 300 304). Thousand Oaks, CA: Sage.

Partnership for a Drug Free America. (2000). Partnership attitude tracking study, spring 2000: Teens in grades 7 through 12. New York: Author.

Petty, R. E., \& Cacioppo, J. (1979). Issue involvement can increase or decrease persuasion by enhancing message relevant cognitive responses. Journal of Personality and Social Psychology, 37, 19151926.

Petty, R. E., \& Cacioppo, J. (1986). The Elaboration Likelihood Model of persuasion. In L. Berkowitz (Ed.), Advances in experimental social psychology (Vol. 19, pp. 123 205). New York: Academic Press.

Petty, R. E., Cacioppo, J., \& Goldman, R. (1981). Personal involvement as a determinant of argument based persuasion. Journal of Personality and Social Psychology, 41, 847855.

Petty, R. E., Cacioppo, J., \& Schumann, D. (1983). Central and peripheral routes to advertising effectiveness: The moderating role of involvement. Journal of Consumer Research, 10(2), 135146.

Petty, R. E., Ostrom, T. M., \& Brock, T. C. (1981). Historical foundations of the cognitive response approach to attitudes and persuasion. In R. E. Petty, T. M. Ostrom, \& T. C. Brock (Eds.), Cognitive responses in persuasion (pp. 5 29). Hillsdale, NJ: Lawrence Erlbaum.

Petty, R. E., \& Priester, J. R. (1994). Mass media attitude change: Implications of the elaboration likelihood model of persuasion. In J. Bryant \& D. Zillman (Eds.), Media effects: Advances in theory and research (pp. 91 122), Hillsdale, NJ: Lawrence Erlbaum.

Pool, G., Wood, W., \& Leck, K. (1998). The self esteem motive in social influence: Agreement with valued majorities and disagreement with derogated minorities. Journal of Personality and Social Psychology, 75, 967975.

Price, V. (1992). Public opinion. Newbury Park, CA: Sage. 
Rogers, E. (1962). Diffusion of innovations. New York: Free Press.

Rogers, E. (1995). Diffusion of innovations (4th ed.). New York: Free Press.

Rosen, E. (2000). The anatomy of buzz: How to create word of mouth marketing. New York: Random House.

Schachter, S. (1951). Deviation, rejection, and communication. Journal of Abnormal and Social Psychology, 46, 190207.

Snyder, L. B., \& Hamilton, M. A. (2002). Meta analysis of U.S. health campaign effects on behavior: Emphasize enforcement, exposure, and new information, and beware the secular trend. In R. Hornik (Ed.), Public health communication: Evidence for behavior change (pp. 357 383). Hillsdale, NJ: Lawrence Erlbaum.

Stephenson, M., \& Palmgreen, P. (2001). Sensation seeking, perceived message sensation value, personal involvement, and processing of anti marijuana PSAs. Communication Monographs, 68(1), 4971.

Tajfel, H. (1981). Human groups and social categories: Studies in social psychology. Cambridge, UK: Cambridge University Press.

Tanford, S., \& Penrod, S. (1984). Social influence model: A formal integration of research on majority and minority influence processes. Psychological Bulletin, 95, 189225.

Turner, J. C. (1991). Social influence. Pacific Grove, CA: Brooks/Cole.

Wechsler, H., Nelson, T. E., Lee, J. E., Seibring, M., Lewis, C., \& Keeling, R. P. (2003). Perception and reality: A national evaluation of social norms marketing interventions to reduce college students' heavy alcohol use. Quarterly Journal of Studies on Alcohol, 64, 484494.

Weimann, G. (1994). The influentials: People who influence peoples. Albany: State University of New York Press.

Werch, C. E., \& Owen, D. M. (2002). Iatrogenic effects of alcohol and drug prevention programs. Journal of Studies on Alcohol, 63, 581590.

Williams, S., \& Ryckman, R. M. (1984). The effects of sensation seeking and misattribution of arousal on dyadic interactions between similar or dissimilar strangers. The Journal of Mind and Behavior, 5, 337350.

Wood, W., Kallgren, C. A., \& Priesler, R. M. (1985). Access to attitude relevant information in memory as a determinant of persuasion: The role of message attributes. Journal of Experimental Social Psychology, 21(1), 7385.

Wood, W., Lundgren, S., Ouellette, J. A., Busceme, S., \& Blackstone, T. (1994). Minority influence: A meta analytic review of social influence processes. Psychological Bulletin, 115(3), 323345.

Yanovitzky, I. (2005). Sensation seeking and adolescent drug use: The mediating role of association with deviant peers and pro drug discussions. Health Communication, 17(1), 6789.

Yzer, M., Cappella, J., Fishbein, M., Hornik, R., \& Ahern, K. (2003). The effectiveness of gateway communications in anti marijuana campaigns. Journal of Health Communication, 8(2), 129143.

Zuckerman, M. (1994). Behavioral expressions and biosocial bases of sensation seeking. New York: Cambridge University Press.

Zuckerman, M., \& Link, K. (1968). Construct validity for the sensation seeking scale. Journal of Consulting and Clinical Psychology, 32, 420426. 